\title{
NUCLEUS PULPOSUS CELLS SYNTHESIZE A FUNCTIONAL EXTRACELLULAR MATRIX AND RESPOND TO INFLAMMATORY CYTOKINE CHALLENGE FOLLOWING LONG-TERM AGAROSE CULTURE
}

\author{
Lachlan J. Smith, Joseph A. Chiaro, Nandan L. Nerurkar, Daniel H. Cortes, Sarena D. Horava, Nader M. Hebela ${ }^{1}$,
} Robert L. Mauck, George R. Dodge and Dawn M. Elliott

Department of Orthopaedic Surgery, Perelman School of Medicine, University of Pennsylvania, Philadelphia, PA 19104, USA

${ }^{1}$ Department of Veterans Affairs Medical Center, Philadelphia, PA, 19104, USA

Abstract

Intervertebral disc degeneration is characterized by a cascade of cellular, biochemical and structural changes that may lead to functional impairment and low back pain. Interleukin-1 beta (IL-1 $\beta$ ) is strongly implicated in the etiology of disc degeneration, however there is currently no direct evidence linking IL- $1 \beta$ upregulation to downstream biomechanical changes. The objective of this study was to evaluate long-term agarose culture of nucleus pulposus (NP) cells as a potential in vitro model system to investigate this. Bovine NP cells were cultured in agarose for 49 days in a defined medium containing transforming growth factor-beta 3, after which both mechanical properties and composition were evaluated and compared to native NP. The mRNA levels of NP cell markers were compared to those of freshly isolated NP cells. Glycosaminoglycan (GAG) content, aggregate modulus and hydraulic permeability of mature constructs were similar to native NP, and aggrecan and SOX9 mRNA levels were not significantly different from freshly isolated cells. To investigate direct links between IL-1 $\beta$ and biomechanical changes, mature agarose constructs were treated with IL-1 $\beta$, and effects on biomechanical properties, extracellular matrix composition and mRNA levels were quantified. IL- $1 \beta$ treatment resulted in upregulation of a disintegrin and metalloproteinase with thrombospondin motifs 4, matrix metalloproteinase-13 and inducible nitric oxide sythase, decreased GAG and modulus, and increased permeability. To evaluate the model as a test platform for therapeutic intervention, cotreatment with IL-1 $\beta$ and IL-1 receptor antagonist (IL-1 ra) was evaluated. IL-1ra significantly attenuated degradative changes induced by IL-1 $\beta$. These results suggest that this in vitro model represents a reliable and cost-effective platform for evaluating new therapies for disc degeneration.

Key Words: Intervertebral disc, nucleus pulposus, agarose, interleukin-1 beta, interleukin-1 receptor antagonist; biomechanical properties.

*Address for correspondence:

Lachlan J Smith

Department of Orthopaedic Surgery

Perelman School of Medicine

University of Pennsylvania

424 Stemmler Hall

$36^{\text {th }}$ and Hamilton Walk

Philadelphia, PA, 19104 USA

Telephone Number +1 215-898-8653

FAX Number: +1 215-573-2133

E-mail: lachlans@mail.med.upenn.edu
Intervertebral disc degeneration is characterized by a cascade of cellular, biochemical and structural changes that may ultimately lead to functional impairment and low back pain. This cascade begins in the central nucleus pulposus (NP), where decreasing proteoglycan content and an associated reduction in hydrostatic pressure impair the ability of the NP to perform its most critical role: the even distribution and transfer of compressive loads between the vertebral bodies (Adams et al., 1996; Roughley, 2004).

Inflammatory cytokines play key roles in the etiology of disc degeneration (Freemont, 2009). Interleukin-1 beta (IL-1 $\beta$ ) in particular is highly expressed by cells in the degenerate NP (Le Maitre et al., 2005), and has been shown to be associated with increased activity of downstream catabolic enzymes, including those that degrade proteoglycans and collagen (Le Maitre et al., 2004; Le Maitre et al., 2007c; Hoyland et al., 2008). While previous studies have demonstrated that IL-1 $\beta$ induces a catabolic response by NP cells at the molecular level, to date no studies have reported a direct link between these molecular changes and altered biomechanical function. One reason for this is that there is currently a lack of appropriate mimetic model systems that facilitate simultaneous evaluation of cellular events, and molecular, compositional and biomechanical changes associated with disc degeneration.

The molecular and biosynthetic characteristics of NP cells have been studied extensively in three-dimensional culture (Yang and Li, 2009). The majority of such studies have used alginate, a hydrogel that preserves the NP cell phenotype, however there is evidence that NP cells are not able to assemble a functional extracellular matrix in alginate (Baer et al., 2001). A smaller number of studies have used agarose, but have been of relatively short duration, and have not evaluated mechanical properties (Horner and Urban, 2001; Sato et al., 2001; Shen et al., 2003; Gokorsch et al., 2004; Zeiter et al., 2009; Fernando et al., 2011). Long-term agarose culture has been extensively used to study the behavior of articular cartilage chondrocytes in vitro (Buschmann et al., 1992; Mauck et al., 2000; Lima et al., 2008; Huang et al., 2010). In the presence of specialized chemically defined media, chondrocytes cultured in agarose synthesize mechanically robust, cartilage-like constructs. Due to phenotypic similarities with chondrocytes (Sive et al., 2002), it was hypothesized that mature NP cells would respond in a similar way when cultured under the same conditions.

The first objective of this study, therefore, was to engineer an in vitro, biological nucleus pulposus-like 
construct which reflects the characteristics of the native tissue, including biochemical composition, biomechanical properties and mRNA levels, using long term culture in agarose and a chemically defined medium. The second objective was to investigate effects of IL- $1 \beta$ treatment on the biomechanical properties, extracellular matrix composition and mRNA levels of functionally mature NP cell-seeded agarose constructs. Interleukin 1 receptor antagonist (IL-1ra) has shown early promise as a potential therapy for disc degeneration, by inhibiting IL-1 $\beta$ activity (Le Maitre et al., 2007a). The final objective of this study was to examine the ability of IL-1 ra to attenuate functional matrix degradation induced by IL- $1 \beta$.

\section{Methods}

\section{Cell isolation and agarose culture}

Four caudal intervertebral discs were obtained from each of four fresh adult bovine tails (16 discs total), purchased from a local slaughterhouse according to Institutional guidelines. NP tissue was isolated, placed in high glucose Dulbecco's Modified Eagle Medium (DMEM) containing $2 \%$ penicillin/streptomycin/fungizone (PSF) and incubated overnight at $37{ }^{\circ} \mathrm{C}$ to verify no bacterial growth. Each sample was then digested for $1 \mathrm{~h}$ in $2.5 \mathrm{mg} / \mathrm{mL}$ pronase (66 PUK $/ \mathrm{mg}$ solid), followed by $4 \mathrm{~h}$ in $0.5 \mathrm{mg} / \mathrm{mL}$ collagenase $\left(>125 \mathrm{CDU} / \mathrm{mg}\right.$ solid), both at $37^{\circ} \mathrm{C}$, then filtered through a $70 \mu \mathrm{m}$ cell strainer. Three aliquots $\left(2 \times 10^{5}\right.$ cells) of these 'freshly isolated' cells were retained for comparative mRNA experiments. The remaining isolated cells were expanded in monolayer in high glucose DMEM containing $10 \%$ fetal bovine serum (FBS) and $1 \%$ PSF. Passage 2 cells from all donor animals were combined to minimize the effects of inter-donor biological variation, and suspended in a chemically defined medium comprised of high glucose DMEM supplemented with $1 \%$ PSF, $0.1 \mu \mathrm{M}$ dexamethasone, $50 \mathrm{mg} / \mathrm{mL}$ ascorbate 2-phosphate, $40 \mathrm{mg} /$ $\mathrm{mL}$ L-proline, $100 \mathrm{mg} / \mathrm{mL}$ sodium pyruvate, ITS Premix $(6.25 \mu \mathrm{g} / \mathrm{mL}$ insulin, $6.25 \mu \mathrm{g} / \mathrm{mL}$ transferrin, $6.25 \mathrm{ng} / \mathrm{mL}$ selenious acid), $1.25 \mathrm{mg} / \mathrm{mL}$ bovine serum albumin (BSA), $5.35 \mu \mathrm{g} / \mathrm{mL}$ linoleic acid and $10 \mathrm{ng} / \mathrm{mL}$ transforming growth factor-beta 3 (TGF- $\beta 3$ ). This chemically defined medium has been demonstrated previously to facilitate enhanced matrix deposition over serum alone containing media by both NP cells and articular chondrocytes in three-dimensional culture (Mauck et al., 2006; Reza and Nicoll, 2010b). The cell solution was mixed with an equal volume of $4 \%$ sterile, low gelling temperature agarose at a temperature of $49{ }^{\circ} \mathrm{C}$ such that the final seeding density was $2.0 \times 10^{7}$ cells $/ \mathrm{mL}$. While this cell density is higher than the native adult NP (Maroudas et al., 1975), it was necessary to achieve sufficient levels of functional matrix deposition that would facilitate measurable changes in mechanical properties following cytokine treatments. Gels were cast between 2 glass plates to obtain a slab $2.25 \mathrm{~mm}$ thick and individual constructs $4 \mathrm{~mm}$ in diameter were then cut using a biopsy punch. Constructs were cultured for 49 days. Agarose (catalogue no. A4018, batch no. 109K1232), collagenase, dexamethasone, L-proline, ascorbate 2-phosphate, linoleic acid and BSA were purchased from Sigma-Aldrich (St Louis, MO, USA); DMEM, PSF (catalogue no. 15240), sodium pyruvate and FBS (lot \#769376) from Invitrogen (Carlsbad, CA, USA); pronase from Merck (Darmstadt, Germany); TGF- $\beta 3$ from R\&D Systems (Minneapolis, MN, USA); ITS Premix from BD Biosciences (Bedford, MA, USA); and sodium pyruvate from Mediatech Inc (Manassas, VA, USA).

Mechanical properties, biochemical composition, histology and mRNA levels were evaluated after 14 and $49 \mathrm{~d}$, and compared with day one properties and native tissue properties.

\section{IL-1 $\beta$ and IL-1ra treatment}

For samples undergoing cytokine treatments, TGF $\beta-3$ was removed from the media $7 \mathrm{~d}$ prior to commencing treatments (i.e., at day 42 of agarose culture). Constructs ( $n$ $=16$ per group) were treated with defined media (without TGF $\beta$-3) supplemented with a single dose of recombinant human IL-1 $\beta(10 \mathrm{ng} / \mathrm{mL})$, IL-1ra $(100 \mathrm{ng} / \mathrm{mL})$, or both IL-1 $\beta$ and IL-1 ra together (R\&D Systems). Dosages were selected based on the results of previous studies (Le Maitre et al., 2005; Le Maitre et al., 2007a) and our own pilot studies. Samples were harvested after 3 d. Mechanical properties, biochemical composition and mRNA levels were evaluated and compared to untreated controls as described below.

\section{Mechanical testing}

Constructs $(n=5)$ at 1,14 and 49 d of culture, and from each treatment group were tested in confined compression. The testing system consisted of an acrylic chamber fixed above a porous, stainless steel platen $(10 \mu \mathrm{m}$ pore size, 50 $\%$ void ratio) within a testing bath filled with culture media (without TGF $\beta-3$ ). To account for variability in sample diameter following agarose culture, six confinement chambers were constructed ranging in diameter from 4.00 to $4.50 \mathrm{~mm}$. Prior to testing, the diameter of each construct was measured using digital calipers and matched to a confinement chamber. Compression was applied using an impermeable ceramic indenter, size-matched to the confinement chamber, attached to a mechanical testing system fitted with a $5 \mathrm{~N}$ load cell (Instron; Norwood MA, USA). Samples were initially subjected to a $0.02 \mathrm{~N}$ preload held for $500 \mathrm{~s}$, followed by a stress relaxation test. This consisted of $10 \%$ strain, calculated based on the sample thickness following preload, applied at a rate of $0.05 \%$ per second, followed by relaxation to equilibrium for 10 min. Aggregate modulus $\left(\mathrm{H}_{\mathrm{A}}\right)$ was calculated as the final, equilibrium stress (equilibrium force/sample area) divided by the applied strain. Hydraulic permeability $\left(\mathrm{k}_{0}\right)$ was calculated from the relaxation data using linear biphasic theory, assuming material isotropy, as described previously (Soltz and Ateshian, 1998).

\section{Biochemical composition}

Following mechanical testing, samples were weighed and digested overnight in papain at $60^{\circ} \mathrm{C}$. Digests were assayed for DNA content using the PicoGreen assay (Invitrogen), sulfated GAG content using the dimethylmethylene blue (DMMB) technique, and collagen (following acid hydrolysis) using the p-diaminobenzaldehyde/ 
Table 1: PCR primer sequences.

\begin{tabular}{|c|c|c|c|c|c|c|}
\hline Primer & $\begin{array}{c}\text { Accession } \\
\text { Number }\end{array}$ & $\begin{array}{c}\text { Direction } \\
\left(5^{\prime}->3^{\prime}\right)\end{array}$ & Sequence & $\begin{array}{l}\text { Tm } \\
\left({ }^{\circ} \mathbf{C}\right)\end{array}$ & $\begin{array}{l}\text { Product } \\
\text { Length }\end{array}$ & Source \\
\hline \multirow{2}{*}{$A C A N$} & \multirow{2}{*}{ NM_173981.2 } & $\mathrm{F}$ & CCTGAACGACAAGACCATCGA & 54.29 & \multirow{2}{*}{101} & \multirow{8}{*}{$\begin{array}{r}\text { (Fitzgerald } \\
\text { et al., 2006) }\end{array}$} \\
\hline & & $\mathrm{R}$ & TGGCAAAGAAGTTGTCAGGCT & 54.48 & & \\
\hline \multirow{2}{*}{ ADAMTS4 } & \multirow{2}{*}{ NM_181667.1 } & $\mathrm{F}$ & AACTCGAAGCAATGCACTGGT & 54.96 & \multirow{2}{*}{149} & \\
\hline & & $\mathrm{R}$ & TGCCCGAAGCCATTGTCTA & 53.16 & & \\
\hline \multirow{2}{*}{ COL1A2 } & \multirow{2}{*}{ NM_174520.2 } & $\mathrm{F}$ & GGTAGCCATTTCCTTGGTGGTT & 54.84 & \multirow{2}{*}{102} & \\
\hline & & $\mathrm{R}$ & AATTCCAAGGCCAAGAAGCATG & 53.85 & & \\
\hline \multirow{2}{*}{ COL2A1 } & \multirow{2}{*}{ NM_001113224.1 } & $\mathrm{F}$ & AAGAAGGCTCTGCTCATCCAGG & 56.09 & \multirow{2}{*}{124} & \\
\hline & & $\mathrm{R}$ & TAGTCTTGCCCCACTTACCGGT & 57.04 & & \\
\hline \multirow{2}{*}{ COL6A2 } & \multirow{2}{*}{ NM_001075126.1 } & $\mathrm{F}$ & CTGGAGAGCCTGGACAGAAG & 53.64 & \multirow{2}{*}{95} & \multirow{2}{*}{$\begin{array}{l}\text { (Dimicco et } \\
\text { al., 2007) }\end{array}$} \\
\hline & & $\mathrm{R}$ & GCCTTTGAAACCAGGAACAC & 51.77 & & \\
\hline \multirow{2}{*}{$G A P D H$} & \multirow{2}{*}{ NM_001034034.1 } & $\mathrm{F}$ & ATCAAGAAGGTGGTGAAGCAGG & 54.61 & \multirow{2}{*}{101} & \multirow{2}{*}{$\begin{array}{r}\text { (Fitzgerald } \\
\text { et al., 2006) }\end{array}$} \\
\hline & & $\mathrm{R}$ & TGAGTGTCGCTGTTGAAGTCG & 55.17 & & \\
\hline \multirow{2}{*}{ INOS } & \multirow{2}{*}{ NM_001076799.1 } & $\mathrm{F}$ & GTAACAAAGGAGATAGAAACAACAGG & 52.30 & \multirow{2}{*}{146} & \multirow{2}{*}{ This paper } \\
\hline & & $\mathrm{R}$ & CAGCTCCGGGCGTCAAAG & 55.52 & & \\
\hline \multirow{2}{*}{ KRT8 } & \multirow{2}{*}{ NM_001033610.1 } & $\mathrm{F}$ & CCGAGTCCTCTGATGTCCTGTCCA & 59.23 & \multirow{2}{*}{86} & \multirow{2}{*}{ This paper } \\
\hline & & $\mathrm{R}$ & GCTCCATCTGCAAGGAGCCAATGA & 59.29 & & \\
\hline \multirow{2}{*}{$M M P 13$} & \multirow{2}{*}{ NM_174389.2 } & $\mathrm{F}$ & TGGTCCAGGAGATGAAGACC & 52.51 & \multirow{2}{*}{80} & \multirow{2}{*}{$\begin{array}{l}\text { (Fitzgerald } \\
\text { et al., 2006) }\end{array}$} \\
\hline & & $\mathrm{R}$ & TGGCATCAAGGGATAAGGAA & 50.22 & & \\
\hline \multirow{2}{*}{ SOX9 } & \multirow{2}{*}{ XR_083993.1 } & $\mathrm{F}$ & TGAAGAAGGAGAGCGAGGAG & 52.72 & & \\
\hline & & $\mathrm{R}$ & CTTGTTCTTGCTCGAGCCGTTGA & 57.90 & 128 & This paper \\
\hline
\end{tabular}

chloramine-T technique for hydroxyproline. Collagen content was calculated assuming a ratio of hydroxyproline to collagen of 1:10 (Nimni, 1983). DNA content was normalized per construct, and GAG and collagen were normalized to construct wet weight. For treatment groups, media aliquots $(n=5)$ were also analyzed for GAG content (normalized per construct) using the DMMB assay.

\section{mRNA levels}

Nine constructs from each culture and treatment group pooled into three groups of three, and the three samples of freshly isolated cells, were used for mRNA analyses. RNA was isolated via two sequential extractions in TRIZOL/ chloroform (Invitrogen) and spectrophotometrically quantified (ND-1000; Nanodrop Technologies, Wilmington, DE, USA). Reverse transcription was performed on $1 \mu \mathrm{g}$ of RNA with random hexamers using a Superscript II kit (Invitrogen) in a $20 \mu \mathrm{L}$ volume.

To determine the degree to which the NP cells recovered and/or maintained their phenotype in three-dimensional culture following monolayer expansion, the mRNA levels of aggrecan (ACAN), collagen II (COL2A1), collagen I (COL1A2), collagen VI (COL6A2), SOX9 and cytokeratin 8 (KRT8) after 1, 14, and $49 \mathrm{~d}$ of culture in agarose were measured and compared to the mRNA levels of freshly isolated NP cells. ACAN, COL2A1 and SOX9 are general phenotype markers that NP cells share with cartilage chondrocytes, while KRT8 is an NP cell specific marker (Minogue et al., 2010). For treatment groups, we additionally examined mRNA levels of matrix metalloproteinase 13 (MMP13), a disintegrin and metalloproteinase with thrombospondin motifs
4 (ADAMTS4), and inducible nitric oxide synthase (iNOS). Primer sequences are provided in Table 1. Primer specificities were confirmed by performing conventional polymerase chain reaction (PCR) and determining amplicon size on agarose gel electrophoresis of the products on a $3 \% \mathrm{w} / \mathrm{v}$ agarose gel stained with ethidium bromide. Optimal annealing temperatures were determined by performing a temperature gradient from $60{ }^{\circ} \mathrm{C}$ to 50 ${ }^{\circ} \mathrm{C}$ using conventional PCR as above. Quantitative PCR was subsequently performed on an Applied Biosystems 7500 system using SYBR Green reagents (Applied Biosystems, Carlsbad, CA, USA). Absolute mRNA levels were calculated from standard curves, normalized to glyceraldehyde 3-phosphate dehydrogenase (GAPDH), and expressed as a ratio to freshly isolated cells $(1,14$ and $49 \mathrm{~d}$ agarose culture groups) or untreated constructs (treatment groups).

\section{Histology}

To assess uniformity of the distribution of the synthesized extracellular matrix, 2 samples from the 14 and $49 \mathrm{~d}$ culture groups were fixed in $10 \%$ buffered formalin immediately at harvest and processed for histology in paraffin. $7 \mu \mathrm{m}$ thick sections were stained with either Alcian blue or picrosirius red to demonstrate GAG or collagen respectively.

\section{Native bovine NP samples}

Native bovine NP samples were obtained and properties compared with those of engineered constructs. Samples for biomechanical testing $(n=4)$ were trimmed on a freezing stage microtome to a uniform thickness of approximately $2.5 \mathrm{~mm}$. A biopsy punch was then used to core a central 



Fig. 1. Alcian blue (left) and picrosirius red (right) staining after 14 and $49 \mathrm{~d}$ of agarose culture showing progressive accumulation of GAG and collagen. Scale bars $=200 \mu \mathrm{m}$.

$4 \mathrm{~mm}$ diameter plug, and samples were tested in confined compression using the protocol described. Samples for biochemistry were processed identically to agarose constructs and assayed for GAG and collagen.

\section{Statistical analysis}

All results are presented as mean \pm standard deviation. Properties of samples after 14 and $49 \mathrm{~d}$ of agarose culture were compared to day one properties using unpaired Student's $t$-tests. 1, 14 and 49 d properties were compared to native NP properties using unpaired Student's $t$-tests. To confirm that removal of TGF $\beta-3$ at day 42 had no effect, properties of samples cultured under these conditions were compared to those of samples cultured with TGF $\beta-3$ for the full 49 days using unpaired Student's $t$-tests. The mRNA levels for 1, 14 and $49 \mathrm{~d}$ samples were expressed as a ratio to freshly isolated cells for statistical comparisons. Properties of treated samples were compared to those of untreated samples using unpaired Student's $t$-tests. The mRNA levels for treated samples were expressed as a ratio to untreated for statistical comparisons. Significance was defined as two-tailed $p<0.05$.

\section{Results}

The intensity of GAG and collagen staining increased from 14 to $49 \mathrm{~d}$ of culture in agarose (Fig. 1).

Mean aggregate modulus of constructs increased progressively with culture time, and was significantly greater at $14 \mathrm{~d}(35 \mathrm{kPa})$ and $49 \mathrm{~d}(115 \mathrm{kPa})$ than at $1 \mathrm{~d}(2$ $\mathrm{kPa}$ ) (Fig. 2A). At day 1 of culture, aggregate modulus of constructs was $2 \%$ of the native NP modulus ( $p<$ 0.05 ), $63 \%$ of native after $14 \mathrm{~d}$ culture (not significantly different) and $207 \%$ of native after $49 \mathrm{~d}(p<0.05)$ (Fig. 2A). Hydraulic permeability of constructs decreased progressively with culture time, and was significantly lower at $14 \mathrm{~d}\left(0.76 \mathrm{~mm}^{4} / \mathrm{N} . \mathrm{s} \times 10^{-12}\right)$ and $49 \mathrm{~d}\left(0.04 \mathrm{~mm}^{4} / \mathrm{N}\right.$. $\left.\mathrm{sx} 10^{-12}\right)$ than at $1 \mathrm{~d}\left(0.76 \mathrm{~mm}^{4} / \mathrm{N} . \mathrm{sx} 10^{-12}\right)($ Fig. $2 \mathrm{~B})$. At day 1 , hydraulic permeability of constructs was $2,432 \%$ of the native NP permeability $(p<0.05), 401 \%$ of native after $14 \mathrm{~d}$ culture $(p<0.05)$ and $102 \%$ of native after $49 \mathrm{~d}$ (not significantly different) (Fig. 2B). Removal of TGF $\beta-3$ from the culture medium at $42 \mathrm{~d}$ had no significant effect on either aggregate modulus (Fig. 2A) or hydraulic permeability (Fig. 2B) at $49 \mathrm{~d}$ compared with constructs cultured for the full $49 \mathrm{~d}$ with TGF $\beta-3$. 

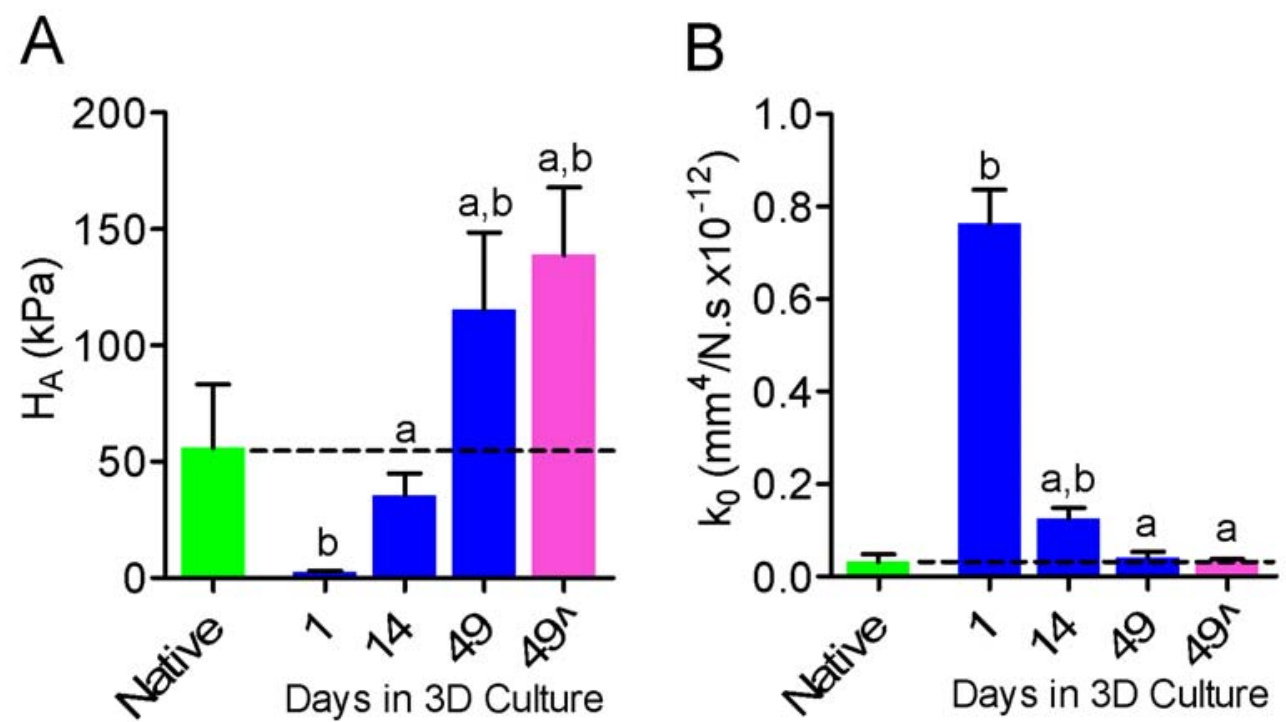

Fig. 2. Mechanical properties of NP cell-seeded agarose constructs with culture duration and in comparison to

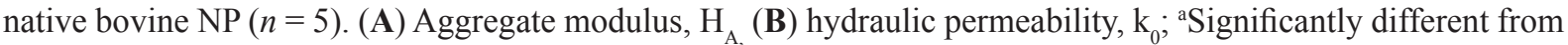
day $1, p<0.05$; ${ }^{b}$ significantly different from native NP, $p<0.05$. Dashed lines represent mean native values. $49^{\wedge}$ $=$ TGF- $\beta 3$ removed from media at day 42 .

A

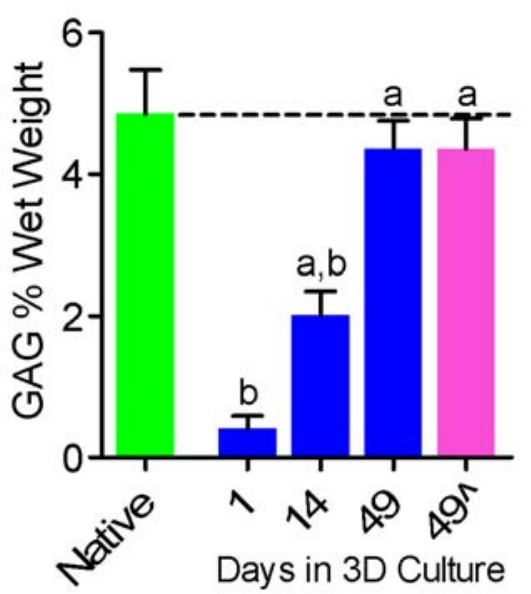

B

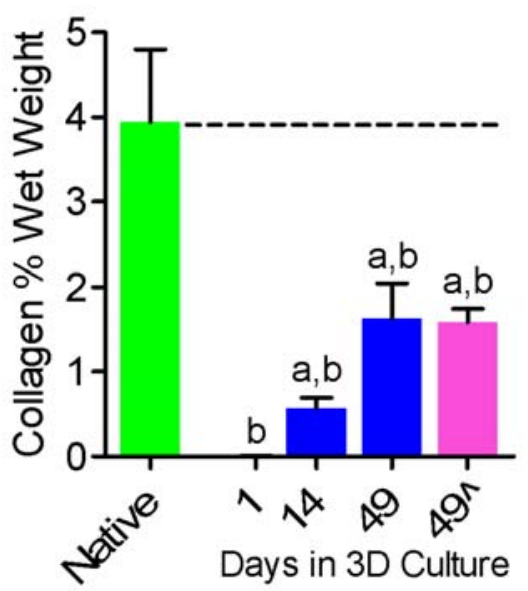

C

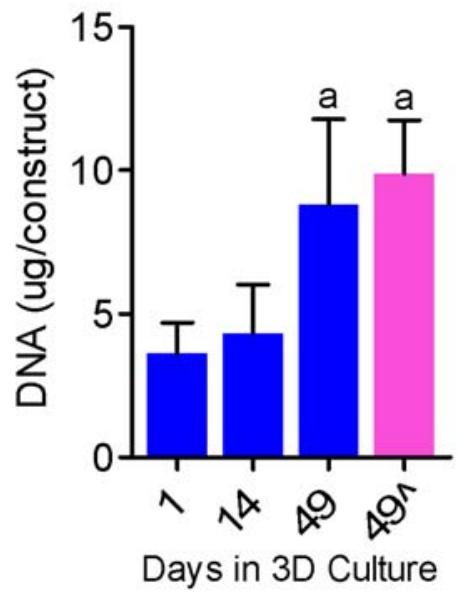

Fig. 3. Biochemical composition of NP cell-seeded agarose constructs with culture duration and in comparison to native bovine NP $(n=5)$. (A) GAG content, (B) Collagen content, (C) DNA content. aSignificantly different from day $1, p<0.05$; ${ }^{\text {b }}$ significantly different from native NP, $p<0.05$. Dashed lines represent mean native values. $49^{\wedge}=$ TGF- $\beta 3$ removed from media at day 42 .

Both GAG and collagen content of constructs increased progressively with culture time, and were significantly greater at $14 \mathrm{~d}$ (2.0 and $0.6 \%$ wet weight respectively) and $49 \mathrm{~d}(4.4 \%$ and $1.6 \%$ wet weight respectively) than at day 1 (0.4 and $0.002 \%$ wet weight respectively) (Figs. $3 \mathrm{~A}, \mathrm{~B})$. At day 1 , GAG content of constructs was $8 \%$ of the native NP GAG content $(p<0.05), 42 \%$ of native after $14 \mathrm{~d}$ culture $(p<0.05)$ and $90 \%$ of native after $49 \mathrm{~d}$ (not significantly different) (Fig. 3A). At day 1, collagen content of constructs was $0.05 \%$ of the native NP collagen content $(p<0.05), 14 \%$ of native after $14 \mathrm{~d}$ culture $(p<$ $0.05)$ and $41 \%$ of native after $49 \mathrm{~d}(p<0.05)$ (Fig. 3B). DNA content of agarose constructs increased progressively with culture time, and was significantly greater at $49 \mathrm{~d}$ than at $14 \mathrm{~d}$ or day 1 (Fig. 3C). Removal of TGF- $\beta 3$ from the culture medium at $42 \mathrm{~d}$ had no significant effect on either GAG, collagen or DNA content (Figs. 3A, B, C) at $49 \mathrm{~d}$ compared with constructs cultured for the full $49 \mathrm{~d}$ with TGF $\beta-3$.

The level of ACAN mRNA at day 1 of agarose culture was $23 \%$ of that of freshly isolated cells $(p<0.05), 43 \%$ after $14 \mathrm{~d}(p<0.05)$ and $171 \%$ after $49 \mathrm{~d}$ (not significantly different) (Fig. 4A). The level of COL2A1 mRNA at day 1 of agarose culture was $0.6 \%$ of that of freshly isolated cells $(p<0.05), 9 \%$ after $14 \mathrm{~d}(p<0.05)$ and $47 \%$ after $49 \mathrm{~d}(p$ $<0.05$ ) (Fig. 4B). The level of COL1A2 mRNA expression 
A
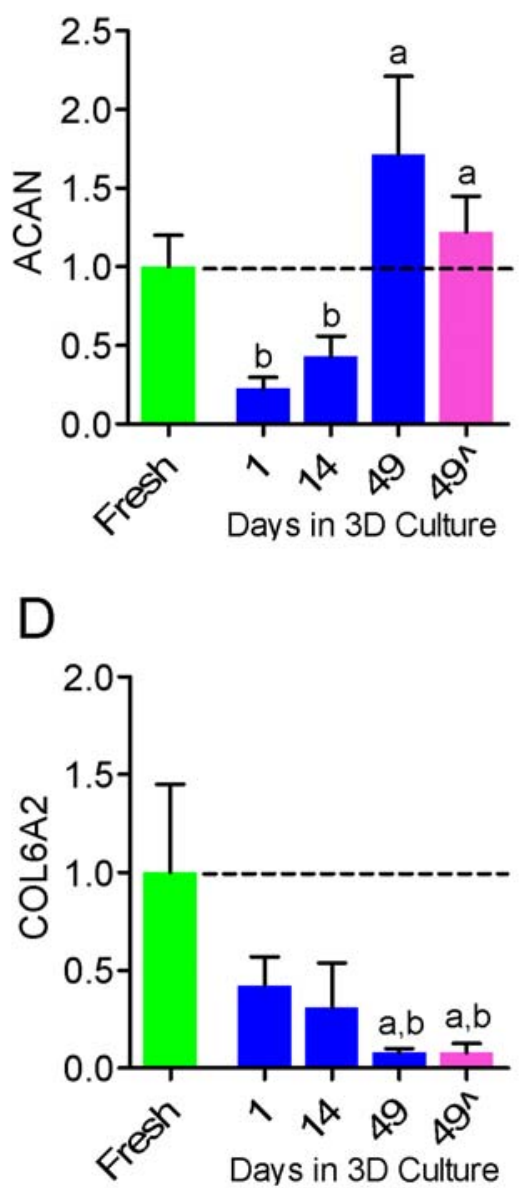

B

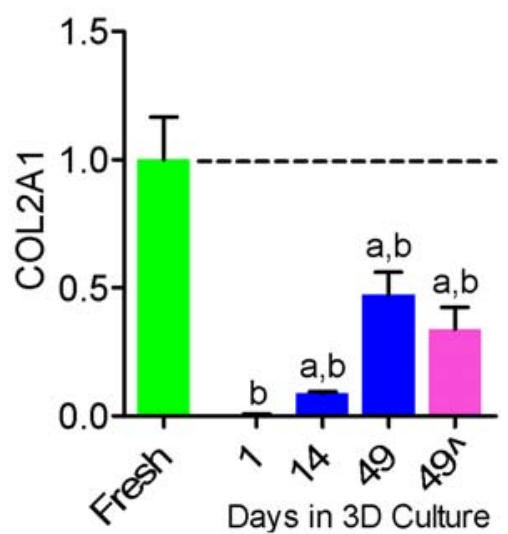

E

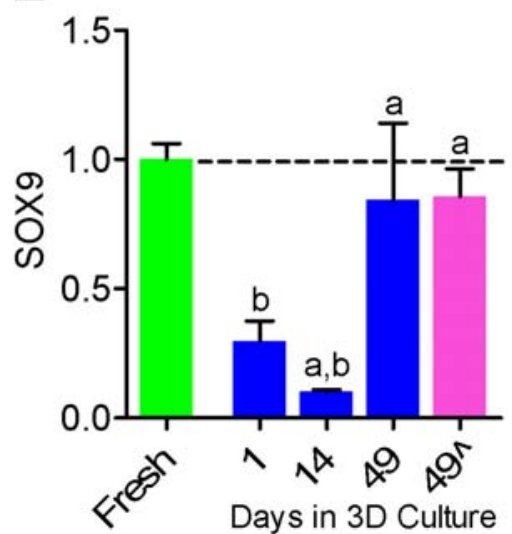

C
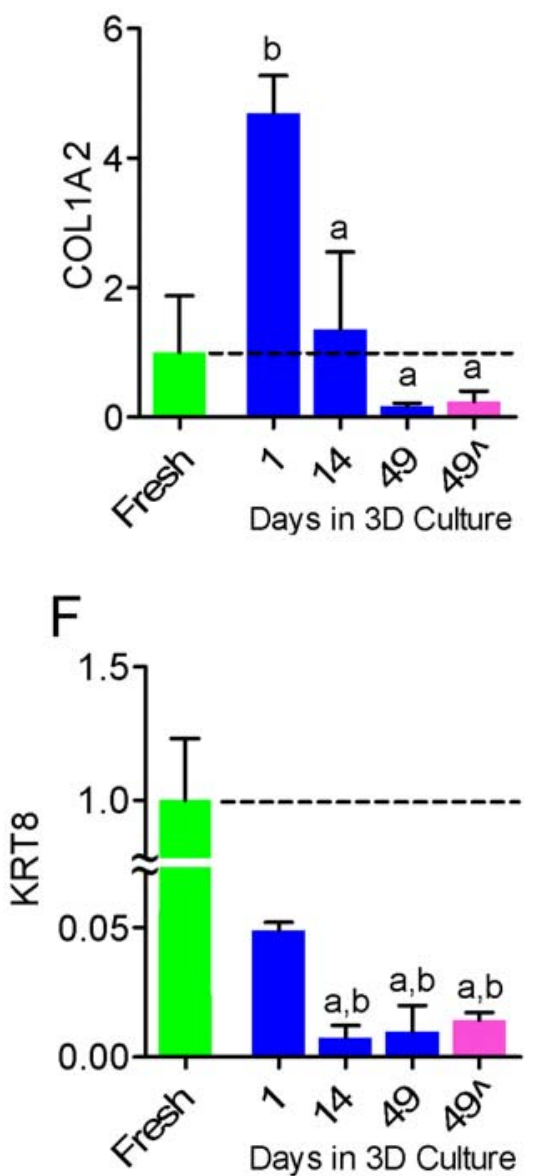

Fig. 4. mRNA levels for NP cell-seeded agarose constructs with culture duration and in comparison to freshly isolated cells $(n=3)$. (A) ACAN, (B) COL2A1, (C) COL1A2, (D) COL6A2, (E) SOX9, (F) KRT8. Values are expressed

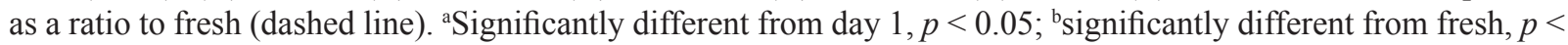
$0.05 ; 49^{\wedge}=\mathrm{TGF}-\beta 3$ removed from media at day 42 .

at day 1 of agarose culture was $468 \%$ of freshly isolated cells $(p<0.05)$, and $135 \%$ and $20 \%$ of fresh at days 14 and 49 respectively (both not significantly different) (Fig. 4C). The ratio of COL1A2 to COL2A1 was 0.06 for freshly isolated cells, and 135, 1.07 and 0.06 for 1,14 and $49 \mathrm{~d}$ of agarose culture. The level of COL6A2 mRNA at days 1 and 14 of agarose culture was $42 \%$ and $31 \%$ of freshly isolated cells respectively (both not significantly different), and $8 \%$ after $49 \mathrm{~d}(p<0.05)$ (Fig. 4D). The level of SOX 9 mRNA at day 1 of agarose culture was $30 \%$ of that of freshly isolated cells $(p<0.05), 10 \%$ after $14 \mathrm{~d}$ $(p<0.05)$ and $84 \%$ after $49 \mathrm{~d}$ (not significantly different) (Fig. 4E). The mRNA level of the NP cell specific marker KRT8 at day 1 of agarose culture was $5 \%$ of that of freshly isolated cells $(p<0.05)$, and $1 \%$ after both $14 \mathrm{~d}$ and $49 \mathrm{~d}$ $(p<0.05$, Fig. 4F). Removal of TGF $\beta-3$ from the culture medium at $42 \mathrm{~d}$ had no significant effect on mRNA levels of ACAN, COL2A1, COL1A2, COL6A2 SOX9 or KRT8 (Figs. 4A-D) at $49 \mathrm{~d}$ compared with samples cultured for the full $49 \mathrm{~d}$ with TGF- $\beta 3$.

For constructs treated with IL-1 $\beta$, aggregate modulus was significantly lower and hydraulic permeability was significantly higher than for untreated controls $(67 \%$ and
$141 \%$ of untreated, respectively, Figs. 5A and B). For constructs treated with both IL-1 $\beta$ and IL-1ra, or IL-1ra alone, neither of these properties was significantly different from those of untreated constructs.

For constructs treated with IL-1 $\beta$, GAG content was 73 $\%$ of untreated ( $p<0.05$, Fig. 5 C) and significantly more GAG was released into the media (Fig. 5D). For constructs treated with both IL-1 $\beta$ and IL-1ra, or IL-1ra alone, GAG content was not significantly different from untreated. Neither collagen nor DNA contents were significantly different from untreated for any of the 3 treatment groups.

ACAN and COL2A1 mRNAs were both downregulated by IL- $1 \beta$ treatment $(23 \%(p<0.05)$ and $8 \%$ (not significant) of untreated respectively, Figs. 6A,B). ACAN and COL2A1 mRNAs were also lower than untreated for samples treated with both IL-1 $\beta$ and IL-1 ra, and IL-1ra alone, but the differences were not statistically significant. COL1A2, COL6A2, SOX9 and KRT8 mRNA levels were not significantly affected by any treatment (not shown). ADAMST4 and iNOS mRNAs were significantly up-regulated by IL-1 $\beta$ treatment $(12,730 \%$ and 38,330 \% of untreated, respectively, Figs. 6C,E, $p<0.05)$. MMP13 mRNA levels were elevated for IL- $1 \beta$ treated samples, 
A



C

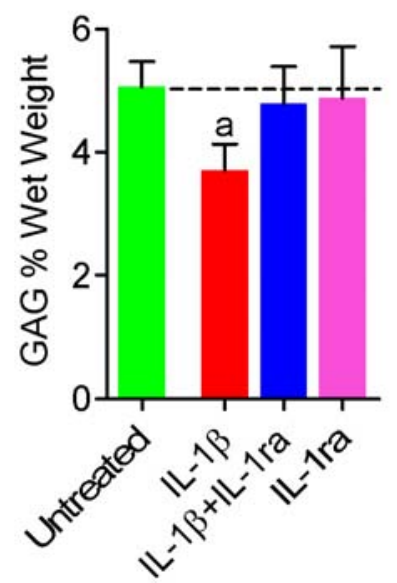

B

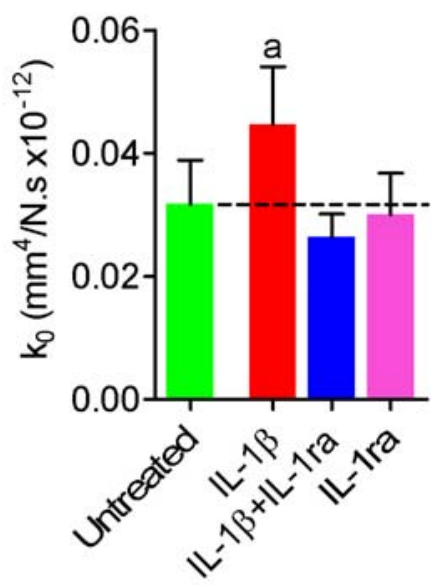

D

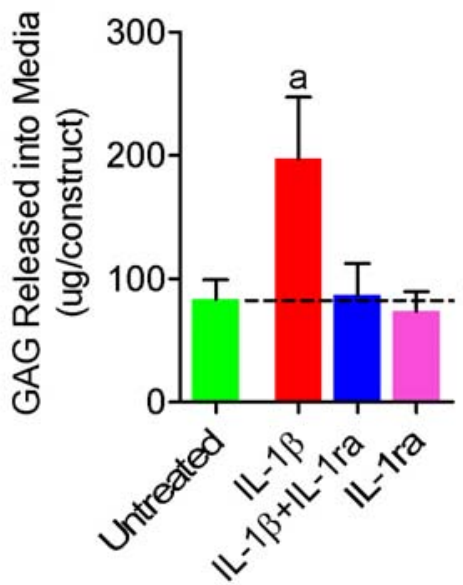

Fig. 5. Mechanical properties and biochemical composition of NP cell-seeded agarose constructs following treatment with IL-1 $\beta$ and IL-1ra $(n=5)$. (A) Aggregate modulus, $\mathrm{H}_{\mathrm{A}}(\mathbf{B})$ Hydraulic permeability, $\mathrm{k}_{0 .}(\mathbf{C})$ GAG content, (D) GAG



but not significantly (Fig 6D). For samples treated with both IL-1 $\beta$ and IL-1ra, and IL-1ra alone, ADAMTS4 and MMP13 mRNA levels were not significantly different from untreated (Figs. 7C,D), while INOS mRNA was elevated with marginal significance $(1,500 \%(p=0.05)$ and 1,110 $\%(p=0.06)$ of untreated respectively, Figure $6 \mathrm{E})$.

\section{Discussion}

In this study we present an engineered three-dimensional model of the nucleus pulposus that exhibits similar composition and mechanical properties to the native tissue. Aggregate modulus and hydraulic permeability of native bovine NP tested in confined compression were of a similar magnitude to that reported previously (Perie et al., 2006), as was the aggregate modulus of acellular $2 \%$ agarose (Mauck et al., 2000). As far as the authors are aware, this is the first study to report mechanical properties of engineered NP tested in confined compression.
Monolayer expansion has been demonstrated previously to affect the phenotype of NP cells. Serial passaging of NP cells has been shown to result in a reduction in the expression of type collagen II and aggrecan (Wang et al., 2001; Kluba et al., 2005). The results of the current study show that these key anabolic markers, and the transcription factor SOX9, are significantly reduced after two-dimensional culture. Even after $14 \mathrm{~d}$ of three-dimensional culture expression levels are still lower than those of freshly isolated cells. Supportive of our model, the phenotype of the agarose-cultured NP cells was restored only after $49 \mathrm{~d}$ of culture in chemically defined media, with levels of aggrecan and SOX9 mRNA similar to levels for freshly isolated cells. Even at this later time point, however, collagen II expression levels remained significantly lower. These mRNA expression level findings complement the findings for extracellular matrix composition, which showed that after $49 \mathrm{~d}$, GAG content was similar to that of native NP, while collagen content was still significantly lower. The ratio of collagen I 

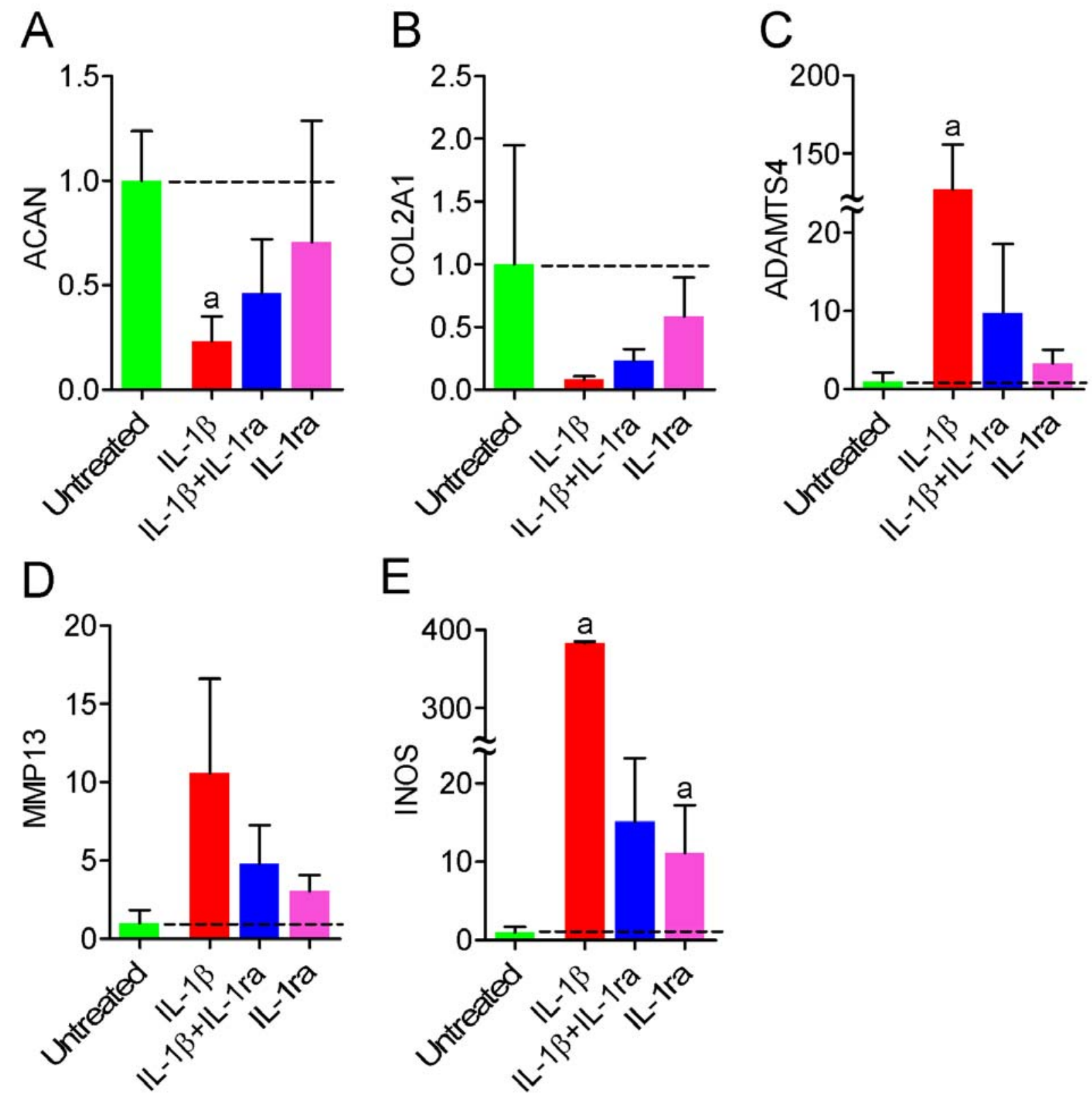

E



Fig. 6. mRNA levels of phenotypic and catabolic markers in NP cell-seeded agarose constructs following treatment with IL-1 $\beta$ and IL-1ra $(n=3)$. (A) ACAN (B) COL2A1, (C) ADAMTS4, (D) MMP13, (E) iNOS. Values are expressed



to collagen II initially increased relative to freshly isolated cells at the beginning of agarose culture, but returned to native levels after $49 \mathrm{~d}$. This finding is consistent with cells that have de-differentiated towards a fibroblastic phenotype in monolayer culture, but re-differentiated upon return to a 3D environment with extended culture time. While KRT8 expression was significantly lower at day 1 of agarose culture than for freshly isolated cells, expression continued to decrease with extended 3D culture time. KRT8 is more highly expressed by notochordal-like NP cells than mature chondrocyte-like NP cells (Minogue et al., 2010). This suggests that our model may promote differentiation towards a more mature-NP cell like phenotype.

The agarose culture system used in this study has been used extensively for the study of articular chondrocytes
(Buschmann et al., 1992; Mauck et al., 2000; Mauck et al., 2003; Kelly et al., 2009). Chondrocytes cultured under these conditions for an extended duration deposit an extracellular matrix with high GAG content and modulus. Furthermore, it has been shown that chondrocytes cultured in this defined medium will synthesize more extracellular matrix than those cultured in serum alone containing media (Mauck et al., 2006). That NP cells and chondrocytes respond to this culture environment in a broadly similar way is in some respects not surprising. Mature NP cells and articular chondrocytes share phenotype similarities, reflected in their mutual high expression of aggrecan, collagen II and SOX9 (Sive et al., 2002). These two cell types however, reside in unique biochemical and micromechanical environments in vivo, and have distinct developmental lineages (Smith et 
al., 2011). As such, identification of unique markers which differentiate these cell types is being actively pursued (Sakai et al., 2009; Minogue et al., 2010; Rutges et al., 2010; Stoyanov et al., 2011). Transcription profiling of NP cells has suggested a handful of candidates, among them cytokeratin 8 , a cytoskeletal protein that is also expressed by notochordal precursors (Gotz et al., 1995; Minogue et al., 2010). An important finding of the current study is that expression levels of cytokeratin 8 , in contrast to aggrecan, collagen II and SOX9, are not restored to native levels in three-dimensional culture. This suggests that additional microenvironmental factors that are present in vivo, such as low oxygen tension, $\mathrm{pH}$ and glucose, mechanical loading, and molecular signaling from adjacent cell populations may be critical regulators of the NP cell phenotype (Stoyanov et al., 2011). The influence of these factors on NP cell specific markers will be the subject of future investigations.

Nucleus pulposus cells from degenerate human discs express IL-1 $\beta$ both in situ and 3 dimensional culture (Le Maitre et al., 2006a; Le Maitre et al., 2007b). Furthermore, a positive correlation has been shown between severity of degeneration and levels of IL- $1 \beta$ expression. NP cells from degenerate human discs also express increased levels of catabolic enzymes, including MMPs -1, 3, 7, 13, and ADAMTS-4 (Le Maitre et al., 2004; Le Maitre et al., 2006a; Le Maitre et al., 2007c). Treatment of human NP cells in vitro by IL- $1 \beta$ results in increased activity of these enzymes and INOS, an important intermodulatory mediator of inflammation (Le Maitre et al., 2005; Zhao et al., 2011), demonstrating an association between the IL-1 $\beta$ and these downstream factors. We have confirmed this association in the current study, demonstrating the treatment of NP cells in agarose cultured with IL-1 $\beta$ results in upregulation of key enzymes that degrade interstitial collagens and proteoglycans, as well as the cell stress marker, INOS. Our results highlight the clinical importance of IL-1 $\beta$ signaling in disc degeneration, by linking these associated downstream molecular events to functionally relevant compositional changes. While treatment with IL-1 $\beta$ also resulted in down regulation of anabolic matrix genes aggrecan and collagen II, SOX9 expression was not significantly affected, a finding supported by a previous study on human cells (Le Maitre et al., 2005). Cytokeratin 8 expression was also unaffected.

While IL- $1 \beta$ is upregulated with disc degeneration, there is no concomitant upregulation of the endogenous inhibitor, IL-1 ra (Le Maitre et al., 2005). IL-1 ra is currently used clinically for the treatment of rheumatoid arthritis and other inflammatory diseases (Gabay et al., 2010), and it has shown early promise in vitro as a treatment for disc degeneration (Le Maitre et al., 2006b; Goupille et al., 2007; Le Maitre et al., 2007a). Using the in vitro model developed in the current study, we have shown that not only does IL-1 ra counteract the deleterious effects of IL-1 $\beta$ at the molecular level, but it effectively inhibits associated compositional and biomechanical changes. To enhance the clinical relevance of these important findings, ongoing work is investigating the effects of introducing IL-1ra to an environment with pre-existing inflammation.
In addition to biological therapies such as IL-1ra, NP tissue engineering is being actively pursued as an alternative strategy for restoring disc function (Chou et al., 2009; Reza and Nicoll, 2010a). The results of the current study indicate that implantation of an engineered, biological construct into a disc space where there is substantial inflammation present will result in a significant reduction in the baseline mechanical properties of that implant. Integrating bioactive molecules, such as IL-1ra, into implant scaffolds may be an effective means of counteracting these effects.

In this study we describe a tissue-engineered model of the nucleus pulposus that closely mimics key functional, compositional and molecular characteristics of the native tissue. This model was used to demonstrate that exposure of NP cells to IL-1 $\beta$ leads to altered mechanical function, primarily due to loss of GAG. Furthermore, it was demonstrated that IL-1ra could effectively inhibit this cascade of catabolic events. In the future, this culture system could be further refined to incorporate additional features of the native NP microenvironment, including low oxygen, glucose and $\mathrm{pH}$, and dynamic loading, all of which could reasonably be expected to further mediate cell behavior. Finally, the model described represents a stable and cost-effective platform for evaluating new therapies for disc degeneration, prior to translation to appropriate in vivo models and ultimately, human clinical use.

\section{Acknowledgements}

This work was funded by Department of Veterans Affairs Merit Grant IOX RX 000211, NIH Grant R01EB002425 and the Penn Center for Musculoskeletal Disorders.

\section{References}

Adams MA, McNally DS, Dolan P (1996) 'Stress' distributions inside intervertebral discs. The effects of age and degeneration. J Bone Joint Surg Br 78: 965-972.

Baer AE, Wang JY, Kraus VB, Setton LA (2001) Collagen gene expression and mechanical properties of intervertebral disc cell-alginate cultures. J Orthop Res 19: 2-10.

Buschmann MD, Gluzband YA, Grodzinsky AJ, Kimura JH, Hunziker EB (1992) Chondrocytes in agarose culture synthesize a mechanically functional extracellular matrix. J Orthop Res 10: 745-758.

Chou AI, Akintoye SO, Nicoll SB (2009) Photocrosslinked alginate hydrogels support enhanced matrix accumulation by nucleus pulposus cells in vivo. Osteoarthritis Cartilage 17: 1377-1384.

Dimicco MA, Kisiday JD, Gong H, Grodzinsky AJ (2007) Structure of pericellular matrix around agaroseembedded chondrocytes. Osteoarthritis Cartilage 15: 1207-1216.

Fernando HN, Czamanski J, Yuan TY, Gu W, Salahadin A, Huang CY (2011) Mechanical loading affects the energy metabolism of intervertebral disc cells. J Orthop Res 29: 1634-1641. 
Fitzgerald JB, Jin M, Grodzinsky AJ (2006) Shear and compression differentially regulate clusters of functionally related temporal transcription patterns in cartilage tissue. J Biol Chem 281: 24095-24103.

Freemont AJ (2009) The cellular pathobiology of the degenerate intervertebral disc and discogenic back pain. Rheumatology (Oxford) 48: 5-10.

Gabay C, Lamacchia C, Palmer G (2010) IL-1 pathways in inflammation and human diseases. Nat Rev Rheumatol 6: $232-241$.

Gokorsch S, Nehring D, Grottke C, Czermak P (2004) Hydrodynamic stimulation and long term cultivation of nucleus pulposus cells: a new bioreactor system to induce extracellular matrix synthesis by nucleus pulposus cells dependent on intermittent hydrostatic pressure. Int J Artif Organs 27: 962-970.

Gotz W, Kasper M, Fischer G, Herken R (1995) Intermediate filament typing of the human embryonic and fetal notochord. Cell Tissue Res 280: 455-462.

Goupille P, Mulleman D, Chevalier X, Goupille P, Mulleman D, Chevalier X (2007) Is interleukin-1 a good target for therapeutic intervention in intervertebral disc degeneration: lessons from the osteoarthritic experience. Arthritis Res Ther 9: 110.

Horner HA, Urban JP (2001) 2001 Volvo Award Winner in Basic Science Studies: Effect of nutrient supply on the viability of cells from the nucleus pulposus of the intervertebral disc. Spine 26: 2543-2549.

Hoyland JA, Le Maitre C, Freemont AJ (2008) Investigation of the role of IL-1 and TNF in matrix degradation in the intervertebral disc. Rheumatology (Oxford) 47: 809-814.

Huang AH, Stein A, Mauck RL (2010) Evaluation of the complex transcriptional topography of mesenchymal stem cell chondrogenesis for cartilage tissue engineering. Tissue Eng Part A 16: 2699-2708.

Kelly TA, Ng KW, Ateshian GA, Hung CT (2009) Analysis of radial variations in material properties and matrix composition of chondrocyte-seeded agarose hydrogel constructs. Osteoarthritis Cartilage 17: 73-82.

Kluba T, Niemeyer T, Gaissmaier C, Grunder T (2005) Human anulus fibrosis and nucleus pulposus cells of the intervertebral disc: effect of degeneration and culture system on cell phenotype. Spine 30: 2743-2748.

Le Maitre CL, Freemont AJ, Hoyland JA (2004) Localization of degradative enzymes and their inhibitors in the degenerate human intervertebral disc. J Pathol 204: 47-54.

Le Maitre CL, Freemont AJ, Hoyland JA (2005) The role of interleukin-1 in the pathogenesis of human intervertebral disc degeneration. Arthritis Res Ther 7: R732-745.

Le Maitre CL, Freemont AJ, Hoyland JA (2006a) Human disc degeneration is associated with increased MMP 7 expression. Biotech Histochem 81: 125-131.

Le Maitre CL, Freemont AJ, Hoyland JA (2006b) A preliminary in vitro study into the use of IL-1Ra gene therapy for the inhibition of intervertebral disc degeneration. Int J Exp Pathol 87: 17-28.

Le Maitre CL, Hoyland JA, Freemont AJ (2007a) Interleukin-1 receptor antagonist delivered directly and by gene therapy inhibits matrix degradation in the intact degenerate human intervertebral disc: an in situ zymographic and gene therapy study. Arthritis Res Ther 9: R83.

Le Maitre CL, Hoyland JA, Freemont AJ, Le Maitre CL, Hoyland JA, Freemont AJ (2007b) Catabolic cytokine expression in degenerate and herniated human intervertebral discs: IL-1beta and TNFalpha expression profile. Arthritis Res Ther 9: R77.

Le Maitre CL, Pockert A, Buttle DJ, Freemont AJ, Hoyland JA (2007c) Matrix synthesis and degradation in human intervertebral disc degeneration. Biochem Soc Trans 35: 652-655.

Lima EG, Tan AR, Tai T, Bian L, Stoker AM, Ateshian GA, Cook JL, Hung CT (2008) Differences in interleukin-1 response between engineered and native cartilage. Tissue Eng Part A 14: 1721-1730.

Maroudas A, Stockwell RA, Nachemson A, Urban J (1975) Factors involved in the nutrition of the human lumbar intervertebral disc: cellularity and diffusion of glucose in vitro. J Anat 120: 113-130.

Mauck RL, Soltz MA, Wang CC, Wong DD, Chao PH, Valhmu WB, Hung CT, Ateshian GA (2000) Functional tissue engineering of articular cartilage through dynamic loading of chondrocyte-seeded agarose gels. J Biomech Eng 122: 252-260.

Mauck RL, Wang CC, Oswald ES, Ateshian GA, Hung CT (2003) The role of cell seeding density and nutrient supply for articular cartilage tissue engineering with deformational loading. Osteoarthritis Cartilage 11: 879-890.

Mauck RL, Yuan X, Tuan RS (2006) Chondrogenic differentiation and functional maturation of bovine mesenchymal stem cells in long-term agarose culture. Osteoarthritis Cartilage 14: 179-189.

Minogue BM, Richardson SM, Zeef LA, Freemont AJ, Hoyland JA (2010) Transcriptional profiling of bovine intervertebral disc cells: implications for identification of normal and degenerate human intervertebral disc cell phenotypes. Arthritis Res Ther 12: R22.

Nimni ME (1983) Collagen: structure, function, and metabolism in normal and fibrotic tissues. Semin Arthritis Rheum 13: 1-86.

Perie DS, Maclean JJ, Owen JP, Iatridis JC (2006) Correlating material properties with tissue composition in enzymatically digested bovine annulus fibrosus and nucleus pulposus tissue. Ann Biomed Eng 34: 769-777.

Reza AT, Nicoll SB (2010a) Characterization of novel photocrosslinked carboxymethylcellulose hydrogels for encapsulation of nucleus pulposus cells. Acta Biomater 6: $179-186$

Reza AT, Nicoll SB (2010b) Serum-free, chemically defined medium with TGF-beta(3) enhances functional properties of nucleus pulposus cell-laden carboxymethylcellulose hydrogel constructs. Biotechnol Bioeng 105: 384-395.

Roughley PJ (2004) Biology of intervertebral disc aging and degeneration: involvement of the extracellular matrix. Spine 29: 2691-2699.

Rutges J, Creemers LB, Dhert W, Milz S, Sakai D, Mochida J, Alini M, Grad S (2010) Variations in gene 
and protein expression in human nucleus pulposus in comparison with annulus fibrosus and cartilage cells: potential associations with aging and degeneration. Osteoarthritis Cartilage 18: 416-423.

Sakai D, Nakai T, Mochida J, Alini M, Grad S (2009) Differential phenotype of intervertebral disc cells: microarray and immunohistochemical analysis of canine nucleus pulposus and anulus fibrosus. Spine 34: 14481456.

Sato M, Kikuchi T, Asazuma T, Yamada H, Maeda H, Fujikawa K (2001) Glycosaminoglycan accumulation in primary culture of rabbit intervertebral disc cells. Spine 26: 2653-2660.

Shen B, Melrose J, Ghosh P, Taylor F (2003) Induction of matrix metalloproteinase-2 and -3 activity in ovine nucleus pulposus cells grown in three-dimensional agarose gel culture by interleukin-1beta: a potential pathway of disc degeneration. Eur Spine J 12: 66-75.

Sive JI, Baird P, Jeziorsk M, Watkins A, Hoyland JA, Freemont AJ (2002) Expression of chondrocyte markers by cells of normal and degenerate intervertebral discs. Mol Pathol 55: 91-97.

Smith LJ, Nerurkar NL, Choi KS, Harfe BD, Elliott DM (2011) Degeneration and regeneration of the intervertebral disc: lessons from development. Dis Model Mech 4: 31-41.

Soltz MA, Ateshian GA (1998) Experimental verification and theoretical prediction of cartilage interstitial fluid pressurization at an impermeable contact interface in confined compression. J Biomech 31: 927-934.

Stoyanov JV, Gantenbein-Ritter B, Bertolo A, Aebli N, Baur M, Alini M, Grad S (2011) Role of hypoxia and growth and differentiation factor-5 on differentiation of human mesenchymal stem cells towards intervertebral nucleus pulposus-like cells. Eur Cell Mater 21: 533-547.

Wang JY, Baer AE, Kraus VB, Setton LA (2001) Intervertebral disc cells exhibit differences in gene expression in alginate and monolayer culture. Spine 26: 1747-1752.

Yang X, Li X (2009) Nucleus pulposus tissue engineering: a brief review. Eur Spine J 18: 1564-1572.

Zeiter S, der Werf M, Ito K (2009) The fate of bovine bone marrow stromal cells in hydrogels: a comparison to nucleus pulposus cells and articular chondrocytes. J Tissue Eng Regen Med 3: 310-320.

Zhao CQ, Zhang YH, Jiang SD, Li H, Jiang LS, Dai LY (2011) ADAMTS-5 and intervertebral disc degeneration: the results of tissue immunohistochemistry and in vitro cell culture. J Orthop Res 29: 718-725.

\section{Discussion with Reviewers}

Reviewer I: Treatment with IL-1b caused a decrease in aggrecan and collagen-II expression as well as an increase in ADAMTS4 and iNOS expression. However, treatment with IL-1 ra did not fully recover aggrecan/collagen-II expression and did not fully reduce levels of ADAMTS4/ iNOS down to untreated levels. What do the authors think is the molecular reason for this? Which other pathways may be activated that IL-1ra treatment does not influence? Authors: This is an interesting question. One possible explanation is that the effect of IL-1ra is dose dependent, and that higher dosages of IL-1 ra are required to achieve complete inhibition of IL- $1 \beta$ at $10 \mathrm{ng} / \mathrm{mL}$. Our preliminary studies, however, indicated that for an IL$1 \beta$ concentration of $10 \mathrm{ng} / \mathrm{mL}$, dosages of IL-1 ra above $50 \mathrm{ng} / \mathrm{mL}$ had minimal additional benefit. A more likely explanation is that IL-1 $\beta$ induces native up-regulation of other inflammatory cytokines, such as IL-6 and TNF $\alpha$, which then activate downstream proteases via independent pathways. Importantly, our functional and compositional outcome measures (modulus, permeability and GAG content) were not significantly different from untreated with IL-1ra treatment.

Reviewer II: Why are agarose and alginate (biomaterials from algae) still preferred over other artificial materials e.g. polyethylene glycol (PEG) hydrogels?

Authors: This is a good question. It is not clear why other materials have not been widely explored with regards to NP cell culture. It may be that the field of NP tissue engineering is less mature than cartilage tissue engineering, where PEG and other artificial materials are widely used. In this study, we chose agarose as it is well characterized in our group, and our preliminary findings pointed to its utility in first growing a mature construct, and then altering the construct with respect to inflammatory challenge. We are currently evaluating other materials (including a photo-crosslinkable hyaluronic acid hydrogel), and future studies relating maturation of these cells in a more 'biologic' context will be of great interest. 